\title{
Ambiente virtual de aprendizagem no ensino de Enfermagem: relato de experiência
}

\author{
Virtual learning environment in nursing education: an experience report
}

Ambiente virtual de aprendizaje en la educación de Enfermería: relato de experiencia

\begin{abstract}
Cláudia Prado', Luiz Carlos Santiago", Jaqueline Alcântara Marcelino Silva"', Irene Mari Pereira"', Valéria Marli Leonello"v, Eloá Otrenti ${ }^{i v}$, Heloisa Helena Ciqueto Peres', Maria Madalena Januário Leite

' Universidade de São Paulo, Escola de Enfermagem, Departamento de Orientação Profissional, Curso de Graduação em Enfermagem. São Paulo-SP, Brasil.

"Universidade Federal do Estado do Rio de Janeiro, Escola de Enfermagem Alfredo Pinto, Departamento de Enfermagem Fundamental. Rio de Janeiro-RJ, Brasil.

"' Universidade de São Paulo, Escola de Enfermagem, Programa de Pós-Graduação de Gerenciamento em Enfermagem (Pós-Graduanda). São Paulo-SP, Brasil.

Iv Universidade de São Paulo, Escola de Enfermagem, Programa de Pós-Graduação em Enfermagem (Pós-Graduanda).
\end{abstract} São Paulo-SP, Brasil.

\section{Submissão: 14-10-2010Ａprovação: 19-08-2012 \\ RESUMO}

Novas Tecnologias da Informação/Comunicação oferecem a opção do uso do ambiente virtual de aprendizagem (AVA), o qual possibilita maior interatividade no cotidiano do ensino de enfermagem instigando os educadores a repensarem suas práticas pedagógicas. O objetivo deste estudo foi relatar a experiência do emprego do ambiente virtual no ensino de enfermagem na perspectiva dos estudantes. A disciplina "Educação em Enfermagem: Tendências e Desafios" foi ministrada a 78 estudantes do $4^{\circ}$ semestre do Curso de Graduação em Enfermagem, dos quais 48 responderam um questionário com questões fechadas e, dentre estes, 33 responderam uma questão aberta sobre o uso do AVA. Os alunos consideraram o AVA uma ferramenta facilitadora da aprendizagem, do processo de construção do conhecimento e interação entre alunos, professores e tutores enriquecendo, assim, o compartilhamento de idéias e permitindo uma aprendizagem significativa e colaborativa. O estudo revelou a necessidade de potencialização do uso de AVA no ensino de graduação em enfermagem.

Descritores: Enfermagem; Educação em Enfermagem; Tecnologias Educacionais; Educação em Saúde.

ABSTRACT
New Technologies of Information / Communication offer the option of using a virtual learning environment (VLE), which allows for greater interactivity in daily nursing education urging educators to rethink their teaching practices. The aim of this study was to report the experience of the use of virtual environment in nursing education from the perspective of students. The discipline "Nursing Education: Trends and Challenges" was given to 78 students from the 4th semester of undergraduate nursing, from which 48 answered a questionnaire with closed and, among these, 33 answered an open question about the use of AVA. Students considered the AVA a facilitating tool of learning, the process of knowledge construction and interaction between students, teachers and tutors enriching thus the sharing of ideas and allowing a meaningful and collaborative learning. The study revealed the need for enhancement of use of VLE in teaching undergraduate nursing.

Key words: Nursing; Education, Nursing; Educational Technology; Health Education.

\section{RESUMEN}

Nuevas Tecnologías de la Información / Comunicación ofrecen la opción de usar un entorno de aprendizaje virtual (VLE), lo que permite una mayor interactividad en la educación de enfermería diario instando a los educadores a modificar sus sistemas de enseñanza. El objetivo de este trabajo es presentar la experiencia en el uso de entornos virtuales en la educación de enfermería desde la perspectiva de los estudiantes. La disciplina "Educación de Enfermería: Tendencias y Desafíos" fue ofrecida a 78 alumnos del $4^{\circ}$ semestre de pregrado en enfermería, de los cuales 48 respondieron un cuestionario con preguntas cerradas y, entre ellos, 33 respondieron una pregunta abierta sobre el uso de AVA. Los estudiantes consideran el AVA una herramienta facilitadora del aprendizaje, el proceso de construcción del conocimiento y la interacción entre los estudiantes, los profesores y tutores enriqueciendo así el intercambio de ideas y permitir un aprendizaje significativo y colaborativo. El estudio reveló la necesidad de una mejora de la utilización de VLE en la enseñanza de pregrado en enfermería

Palabras clave: Enfermería; Educación en Enfermería; Tecnología Educativa; Educación en Salud.

\section{AUTOR CORRESPONDENTEＣláudia PradoＥ-mail: claupra@usp.br}




\section{INTRODUÇÃO}

As transformações decorrentes do advento das novas Tecnologias da Informação e Comunicação (TICs), que as sociedades contemporâneas têm experimentado, ultrapassam as fronteiras de suas especificidades e se configuram como ferramentas imprescindíveis para o processamento das diferentes formas de relacionamento entre os indivíduos. Seja no mundo do trabalho, seja no mundo do entretenimento, por exemplo, podemos dizer que nunca um produto tecnológico teve tamanha inserção no cotidiano da rede social, como o verificado a partir das TICs.

Novas maneiras de pensar e de conviver estão sendo elaboradas no mundo das telecomunicações e da informática. As relações entre os homens, o trabalho, a própria inteligência dependem, na verdade da metamorfose de todos os tipos ${ }^{(1)}$.

Dentre os produtos tecnológicos mais utilizados pelo Homem contemporâneo observamos, sem dúvida alguma, o computador como o ícone desta lógica, pois, dentre as suas inúmeras utilidades, com ele aumentamos velozmente o processamento das nossas informações, conseguindo assim o alcance de mecanismos muito ágeis de comunicação jamais vislumbrados pela humanidade.

O computador constituiu-se no veículo apropriado das TICs, assumindo, por meio de sua realidade virtual, uma dimensão impressionante sobre o conjunto de todas as nossas relações. A palavra virtual, "é empregada com freqüência para significar a pura e simples ausência da realidade supondo uma efetuação material, uma presença intangível"(1). Esse termo deriva do latim medieval "virtualis, virtus", significando força, potência. Este "tipo de realidade" é o que existe em potencial, que está por vir, contudo, não em ato, não em atitude, e nos indica duas instâncias a serem consideradas para a realidade: a atualização - realidade real/concreta e a virtualização, isto é, a passagem do atual para o virtual| ${ }^{(2)}$.

A linguagem na telemática contém os novos espaços de expressão da comunicação humana que, mediante a escrita digitalizada da informática, permite-nos, dentre outros aspectos, que a informação desejada possa ocorrer de forma interativa e rápida. Trata-se, portanto de "um elemento fundamental para a prática de qualquer profissão, pois, define os parâmetros da prática, identifica as necessidades e critérios de avaliação"(3).

Este cenário proporcionado pelas TICs, através da informatização das várias formas de comunicação, nos oferece a opção pedagógica pelo ambiente virtual, otimizando desse modo, a relação entre o docente de enfermagem e seu aluno, na medida em que este novo cenário torna viável um repensar sobre nossas práticas educacionais, possibilitando uma nova maneira de interatividade no cotidiano do ensino de enfermagem.

Ambiente virtual pode ser conceituado como "sistemas que sintetizam a funcionalidade de software para Comunicação Mediada por Computador (CMC) e métodos de entrega de material de cursos online". Os autores identificam-no através da sigla em inglês V.L.E. (Virtual Learning Environments) (4). Ambientes virtuais são espaços de aprendizagem que permitem interatividade na práxis pedagógica ${ }^{(5)}$.
Os recursos tecnológicos dos cenários virtuais ajudam na descentralização do próprio trabalho pedagógico rompendo com uma tradição pedagógica clássica, onde a educação é compreendida como transmissão, havendo pouca interatividade entre professor e aluno, de um modo geral ${ }^{(6)}$.

Logo, diante deste mundo em constante transformação tecnológica nos modos de informação e de comunicação, parece-nos imperativo que o professor de enfermagem busque novas estratégias que levem a uma otimização do processo ensino-aprendizagem, compreendendo, essencialmente e cada vez mais, a interação com seu aluno como fator decisivo e inerente à própria práxis de seu trabalho.

Concordamos inteiramente com a necessidade premente de uma "adaptação e uma reconstrução das informações recebidas" (6), pois, o aluno não deve ser considerado como um mero receptor de idéias; há nele uma visão de mundo em constante construção, que por si só, impõe-nos sua condição de elemento também interativo no processo educacional. Para este autor, o emprego de novos recursos tecnológicos pode ter uma boa condição de enriquecimento e ampliação do conhecimento, dependendo de como seja seu planejamento e emprego ${ }^{(6)}$.

Portanto, na perspectiva do uso das Novas Tecnologias da Informação e Comunicação, o objeto do presente artigo é o ambiente virtual como ferramenta de ensino em enfermagem. Seu objetivo central é apresentar a experiência de seu emprego no ensino de enfermagem para alunos do $4^{\circ}$ semestre do Curso de Graduação em Enfermagem da Escola de Enfermagem da Universidade de São Paulo - EEUSP, na disciplina "Educação em Enfermagem: Tendências e Desafios".

\section{RELATO DA EXPERIÊNCIA}

\section{A disciplina}

A disciplina de Educação em Enfermagem: Tendências e Desafios é ministrada pelo Departamento de Orientação Profissional da EEUSP e tem como objetivo destacar o processo educativo como inerente ao trabalho do enfermeiro, analisar as correntes pedagógicas e sua aplicabilidade na enfermagem, conhecer e aplicar o planejamento da ação educativa em enfermagem, elaborar um programa de ação educativa, exercitar a comunicação em situação de ensino-aprendizagem em enfermagem, estimular a auto-avaliação e o processo de capacitação profissional, com a integração entre alunos, professores e profissionais.

Ministrada a 80 alunos do $4^{\circ}$ semestre do Curso de Graduação em Enfermagem, a disciplina tem carga horária total de 60 horas (30 horas de aulas presenciais e 30 horas de aulas virtuais).

A abordagem adotada na disciplina foi a pedagogia crítica ou sócio-cultural, que considera o educando como sujeito elaborador do conhecimento, inserido em um contexto histórico. A expressão mais difundida da perspectiva sócio-cultural é a de Paulo Freire, que considera a construção do saber a partir da realidade vivida pelos sujeitos, onde o conhecimento é elaborado mediante a relação teórica-prática para superar a dicotomia entre o educando e o objeto de aprendizagem. Este concepção educativa é problematizadora, pois envolve a análise, discussão e re-construção dos saberes a partir do 
diálogo em uma relação horizontal professor-aluno que não se restrinja às situações formais de ensino-aprendizagem ao contrário da concepção tradicional de educação, chamada por Freire de bancária ${ }^{(7)}$.

A educação elaborada a partir dos saberes prévios do educando possibilita a constituição da aprendizagem significativa por meio do comportamento crítico-reflexivo de modo que o conhecimento terá aplicabilidade e relevância na vida do educando $^{(8)}$.

\section{A plataforma, as aulas e os tutores}

Buscou-se empregar o Ambiente Virtual de Aprendizagem (AVA) por consistir em uma ferramenta que otimiza o ensino-aprendizagem e a comunicação entre alunos e docentes, possibilitando maior exercício de autonomia e desenvolvimento de novas habilidades. O Moodle (Modular Object-Oriented Dynamic Learning Environment) foi a plataforma escolhida para o desenvolvimento da disciplina por ser um software livre, o qual permite a interação, participação e cooperação dos alunos para a construção do conhecimento, permitindo a aprendizagem colaborativa. Contribui com a disseminação do uso da tecnologia na educação, devido às vantagens oferecidas no que diz respeito, principalmente, a flexibilidade e ao custo para implantação e para utilização ${ }^{(9)}$. Este AVA possibilitou a disponibilização dos temas e material de apoio para o desenvolvimento das aulas presenciais e a realização das tarefas das aulas virtuais.

A interface da disciplina foi organizada de acordo com o cronograma elaborado previamente. Inicialmente encontrase, na abertura da disciplina, o programa, o cronograma, um tutorial do Moodle, para auxiliar as atividades dos alunos, um vídeo motivacional e um fórum permanente para esclarecimento de dúvidas.

Foi utilizada a rota de aprendizagem, que teve por finalidade estruturar o caminho a ser trilhado pelo aluno no decorrer da aula estabelecendo uma comunicação tridimensional entre aluno/professor/conhecimento. Esta estratégia serve como uma ponte, ligando o que o professor deseja e precisa ensinar com aquilo que o aluno precisa aprender ${ }^{(10)}$.

O material de apoio das aulas presenciais foi composto de textos em PDF para leitura complementar. As aulas virtuais continham vídeos motivacionais e/ou ligados aos temas das aulas, textos, apresentação de situações-problema, fóruns de discussão e a ferramenta Tarefa para envio das tarefas propostas.

No primeiro encontro presencial, os alunos foram orientados sobre o uso da plataforma e sua organização. Também foi solicitado para que se dividissem em grupos de 9 ou 10 alunos, para realização das atividades futuras no decorrer da disciplina. Os alunos deveriam atribuir o nome de um animal para designar seus grupos e esclarecer o porque da escolha desse nome, postando o perfil do grupo, no Moodle, juntamente com uma foto do animal escolhido. Cada grupo foi acompanhado ao longo da disciplina por um tutor, que corrigia as tarefas online, realizava a devolutiva para as atividades e principalmente orientava no planejamento e execução da simulação de uma ação educativa.

Neste contexto, o sistema tutorial compreende, um conjunto de ações educativas que contribuem para desenvolver e potencializar as capacidades básicas dos alunos, orientando-os a obterem crescimento intelectual e autonomia, e para ajudá- los a tomar decisões em vista de seus desempenhos e suas circunstâncias de participação como aluno educacional(5).

Ao tutor, é atribuída a função de orientar o processo de aprendizagem dos alunos, assegurando o cumprimento dos objetivos de ensino. Ele deve propor atividades e auxiliar na sua resolução, sugerindo, quando necessário, fontes adicionais de informação educacional ${ }^{(11)}$. Mantém uma relação individualizada e contínua com o aluno no sistema e viabiliza a articulação necessária entre as atividades a serem desenvolvidas e os objetivos propostos. Ele assume papel relevante, atuando como intérprete do curso junto ao aluno, esclarecendo

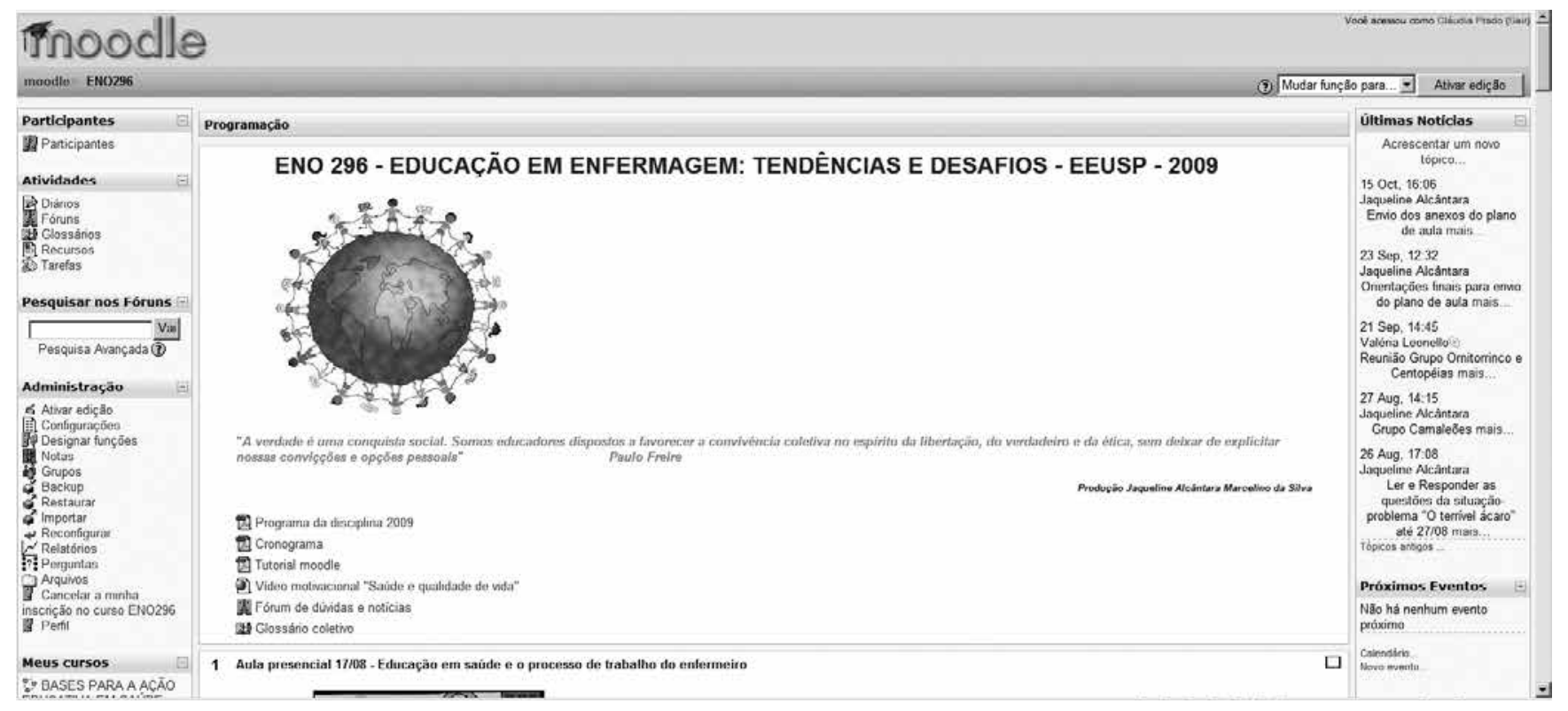

Figura 1 - Interface da disciplina Educação em Enfermagem: Tendências e Desafios 
suas dúvidas, estimulando-o a prosseguir e, ao mesmo tempo, participando da avaliação da aprendizagem educacional ${ }^{(5)}$.

Ao final da disciplina, os alunos desenvolveram um plano de aula e apresentaram uma simulação de ação educativa a partir de situações-problema propostas a cada grupo, estratégia essa utilizada como avaliação da aprendizagem de cada grupo.

\section{Avaliação da disciplina}

A simulação da ação educativa foi avaliada em 360 graus, ou seja, cada grupo foi avaliado pelos tutores, pelos pares (outros grupos) e se auto-avaliaram; todos utilizaram um instrumento que abrangia o planejamento da apresentação, a forma de comunicação (objetividade e clareza), pertinência do conteúdo com o tema, a qualidade do recurso didático, adequação das estratégias aos objetivos da ação, domínio do grupo sobre o tema, interação entre os membros do grupo, criatividade, utilização do tempo previsto, que foi de 40 minutos, e a articulação da ação educativa com o conteúdo apresentado ao longo da disciplina. A participação nas atividades virtuais também foi avaliada por meio de tarefas propostas pelos tutores, bem como o plano da atividade educativa.

Foi solicitado aos alunos que preenchessem um instrumento para avaliar a disciplina e a experiência do ensino aprendizagem por meio de um AVA; dos 80 alunos matriculados na disciplina, 48 responderam ao instrumento. Um dos tópicos dessa avaliação tratava especificamente do Moodle como ambiente virtual de aprendizagem, abrangendo a carga horária virtual oferecida, as orientações para execução de tarefas, as situações-problema, as orientações, interação e devolutivas dos tutores, o tempo proposto para execução das atividades, o desempenho do aluno, o cumprimento dos prazos propostos, a contribuição das atividades propostas para o aprendizado e o uso do Moodle como AVA. Para mensurar as avaliações, foi proposto um modelo tipo escala de Likert, com quatro categorias (Ótimo, Bom, Regular e Ruim).

Foram analisados alguns itens referentes ao AVA adotado na disciplina, onde constatou-se que: em relação à carga horária da disciplina oferecida $45,83 \%$ dos alunos referiram que foi ótima e 43,75\% boa; orientações fornecidas para a execução e devolução das tarefas - 25,0\% ótima e $54,17 \%$ boa; situações-problema (casos) para o desencadeamento das tarefas 31,25\% acharam ótimas e $52.08 \%$ boas; orientações dos tutores para a execução das tarefas - 33,33\% ótima e 39,58\% boa; interação do tutor com seu grupo de alunos - 37,50\% ótima e 37,50\% boa; devolutiva dos tutores para as tarefas postadas - $31,25 \%$ ótima e 50,0\% boa; tempo proposto para execução e devolução das tarefas - $27,08 \%$ ótimo e 50,00\% bom; o próprio desempenho do aluno na realização das tarefas postadas - 33,33\% ótimo e 56,25\% bom; devolução das tarefas propostas nos prazos solicitados - 52,0\% ótima e 41,67\% bom; contribuição das atividades propostas para a aprendizagem - 31,25\% ótimo e $56,25 \%$ bom e uso do Moodle como ambiente virtual de aprendizagem - 37,50\% ótimo e 41,67\% bom.

Os alunos também foram questionados sobre sua opinião acerca do oferecimento de uma disciplina semi-presencial com uso de ambiente virtual de aprendizagem para a formação do enfermeiro, onde destacaram a sua relevância pela possibilidade de estudarem em horários alternativos e a importância de desenvolverem a habilidade de trabalhar em grupo, devido às diversificadas tarefas que podem ser propostas, competência esta necessária ao profissional de enfermagem. Os docentes e tutores avaliaram a disciplina como desafiadora, tendo em vista que exigiu muita dedicação para elaboração do material, grande disponibilidade de tempo para a organização da plataforma e feedback para os alunos nas atividades virtuais.

\section{CONSIDERAÇÕES FINAIS}

Com o uso da plataforma Moodle como AVA na perspectiva teórico-metodológica da abordagem sócio-cultural para aprendizagem da educação em saúde, os tutores tiveram a função de mediar a construção do conhecimento do aluno e não apenas transmitir conteúdos e informação sobre a temática. Tal estratégia possibilitou uma participação discente ativa, despertando a habilidade reflexiva e problematizadora. Dessa forma, o AVA, por meio da mobilização, construção e síntese dos conteúdos trabalhados e das vivências explicitadas, mostrou-se uma estratégia importante e válida para a construção coletiva do conhecimento.

A proposta de ensino semipresencial na formação acadêmica de alunos de enfermagem representou um desafio para estudantes e tutores sendo que, para estes, a condução das aulas virtuais gerou novos desafios em suas práticas pedagógicas. $\mathrm{O}$ envolvimento dos alunos nas atividades virtuais superou as expectativas dos tutores quando comparado ao modelo tradicional de aulas presenciais. A presença do tutor e o vínculo estabelecido contribuíram para o desenvolvimento dos estudantes ao longo das tarefas propostas. Os estudantes mostraram-se comprometidos com sua aprendizagem e no alcance dos resultados alcançados solicitando, frequentemente, as devolutivas dos tutores na busca de aprimoramento de seus saberes.

A inovadora estratégia do uso de AVA no ensino de graduação em enfermagem na EEUSP revelou a necessidade de potencialização de seu uso em outras disciplinas da grade curricular do curso, bem como a continuidade dos novos estudos nessa área de conhecimento.

\section{REFERÊNCIAS}

1. Pierre, Lévy. As tecnologias da inteligência: o futuro do pensamento na era da informática. São Paulo: Editora $34 ; 2002$.

2. Pierre, Lévy. O que é o virtual? São Paulo: Editora 34; 2001.
3. Reis EAA, Denser CPAC, Minatel VF, Bork AMT. Definição de indicadores da assistência de enfermagem a partir dos dados mínimos. In: Anais do $9^{\circ}$ Congresso Brasileiro de Infomática em Saúde; 2004 nov 7-10; 
Ribeirão Preto, Brasil. Ribeirão Preto: SBIS; 2004.

4. Schlemmer E, Fagundes LC. Uma proposta para avaliação de ambientes virtuais de aprendizagem na sociedade em rede. Info Educ Teor Prát 2000;4(2):25-36.

5. Souza CA, Spanhol FJ, Limas JCO; Cassol, MP. Tutoria na educação à distância. In: Anais do $11^{\circ}$ Congresso Internacional de Educação a Distância [evento na internet]. 2004 set 7-10; Salvador, Brasil [acesso em $26 \mathrm{fev}$ 2009] Disponível em: < http://www.abed.org.br/congresso2004/por/htm/088-TC-C2.htm >

6. Froes T, Cardoso A. Práticas Pedagógicas utilizando um Ambiente Virtual de Aprendizagem para Construção Colaborativa do Conhecimento. Rev Ciênc Info 2008;9(2):2 Disponível em: <http://www.dgz.org.br/jun08/Art 03. htm >

7. Pereira ALF. As tendências pedagógicas e a prática educativa nas ciências da saúde. Cad Saúde Pública 2003;19(5):1527-34.
8. Freire P. Pedagogia do Oprimido. Rio de Janeiro: Paz e Terra; 2005.

9. Segundo FR, Ramos DK. Soluções baseadas no uso de software livre: alternativas de suporte tecnológico à educação presencial e a distância. In: Anais do $12^{\circ}$ Congresso Internacional de Educação a Distância [evento na internet]. 2005 set 18-22; Florianópolis, Brasil [acesso em 10 dez 2009]. Disponível em: < http://www.abed.org.br/ congresso2005/por/pdf/099tcc5.pdf/>

10. Schneider El, Medeiros LF, Urbanetz ST. O aprender e o ensinar em EAD por meio de rotas de aprendizagem. In: Anais do $5^{\circ} \mathrm{CIAED}$ [evento na internet]. 2009 set 27-30; Fortaleza, Brasil [acesso em $10 \mathrm{dez} 2009$ ]. Disponível em: <www.abed.org.br/congresso2009/trabalhos1.asp >

11. Maggio M. O tutor na educação a distância. In: Litwin $\mathrm{E}$, organizador. Educação a distância: temas para o debate de uma nova agenda educativa. Porto Alegre: ArtMed, 2001. 